\title{
Daily smoking and lower back pain in adult Canadians: the Canadian Community Health Survey
}

\author{
Fahad Alkherayf $f^{1,2,3}$ \\ Eugene K Wai ${ }^{4,5,6}$ \\ Eve C Tsai ${ }^{1,3,4,6}$ \\ Charles Agbi 1,3,4 \\ 'University of Ottawa, Division \\ of Neurosurgery, Ottawa, Ontario; \\ ${ }^{2}$ University of Ottawa, Department \\ of Clinical Epidemiology, Ottawa, \\ Ontario; ${ }^{3}$ The Ottawa Hospital, Civic \\ campus, Division of Neurosurgery, \\ Ottawa, Ontario; ${ }^{4}$ The Ottawa \\ Hospital, Civic Campus, Spine Unit, \\ Ottawa, Ontario; ${ }^{5}$ The Ottawa \\ Hospital, Civic Campus, Division of \\ Orthopedic Surgery, Ottawa, Ontario; \\ ${ }^{6}$ The Ottawa Hospital Research \\ Institute, Ottawa, Ontario, Canada
}

Correspondence: Fahad Alkherayf Civic Campus Neuroscience C2, 1053 Carling Ave Ottawa, Ontario, KIY 4E9, Canada

$\mathrm{Tel}+\mathrm{I} 613797$ I239

Fax +I 61376I 4767

Email alkherayf@hotmail.com
This article was published in the following Dove Press journal: Journal of Pain Research

24 August 2010

Number of times this article has been viewed

Background: Lower back pain (LBP) is one of the primary causes of disability in the Canadian community. However, only a limited number of studies have addressed the association between daily smoking and LBP in Canada. Of the studies that have explored this association, many had small sample sizes and failed to control for confounders.

Objective: The primary objective of the study was to determine if daily smoking is associated with an increased risk of having LBP. The secondary objectives were to assess the risk for LBP among occasional smokers and to determine the prevalence of LBP in relation to different covariates.

Data and study design: Using the Canadian Community Health Survey (cycle 3.1) data, 73,507 Canadians between the ages of 20 and 59 years were identified. LBP status, smoking level, sex, age, body mass index (BMI), level of activity and level of education were assessed in these subjects.

Methods: Stratified analysis and logistic regression analysis were used to detect effect modifications and to adjust for covariates. Population weight and design were taken into consideration.

Results: The prevalence of LBP was $23.3 \%$ among daily smokers and $15.7 \%$ among nonsmokers. Age and sex were found to be effect modifiers. The association between LBP and daily smoking was statistically significant in all ages and genders; this association was stronger for younger age groups. The adjusted odds ratio for male daily smokers aged 20 to 29 was 1.87 $(95 \% \mathrm{CI}=1.62,2.17)$; findings were similar for women. Occasional smoking slightly increased the odds of having back pain.

Conclusion: Young Canadian daily smokers are at higher risk for LBP. This study also suggests a positive correlation between smoking dose and the risk of LBP. These findings indicate that smoking behavioral modification may have an impact on reducing back pain especially among young adults.

Keywords: lower back pain, smoking, Canadian Community Health Survey, sex, adult Canadians

\section{Introduction}

Low back pain (LBP) is a very common problem in adults. Up to $80 \%$ of adults suffer from LBP at some time in their life. ${ }^{1-4}$ LBP is one of the primary causes of disability in the community and has a large economic impact. ${ }^{5-7}$

Cassidy et al reported that the prevalence of LBP among adult Canadians was $28.4 \%$ in a study of adults in Saskatchewan, and $84.1 \%$ of Saskatchewan adults had experienced LBP at some point during their lifetime. ${ }^{8}$ In 1994, the estimated cost of back and spine disorders in Canada was $\$ 8.1$ billion in Canadian dollars. ${ }^{1}$

Several risk factors for LBP have been reported, including age, sex, genetic predisposition, level of education, activities, socioeconomic status and lifestyle., ${ }^{4-12}$ 
Although some of these factors cannot easily be addressed by medical intervention, lifestyle factors, such as smoking, could be changed by effective intervention. ${ }^{10,13}$

Animal models and biological studies support an association between smoking and intervertebral disc health. ${ }^{14-17}$ In humans, there are many plausible theories to explain why smokers might be prone to increased rates of back pain. One theory is that smoking increases coughing and, thus, may predispose patients to disc herniation. ${ }^{18}$ Other theories focus on reduced blood flow to the discs and vertebral bodies, ${ }^{19}$ while another theory is related to decreased bone mineral density associated with smoking. ${ }^{20}$

Some studies have reported a possible link between smoking and $\mathrm{LBP},{ }^{21-24}$ while others have not reported this link. ${ }^{4,25}$ Goldberg et al reviewed the studies that have looked at the association between cigarette smoking and LBP. ${ }^{26}$ They concluded that the results of these studies were inconsistent, possibly because a large percentage of them did not include enough confounders in their analysis. They found that the most consistent confounders were age, sex, body mass index, level of activity, and level of education.

Smoking prevalence among Canadians in 2007 was reported to be around $19 \%,{ }^{27}$ and according to the latest report from Health Canada, about five million Canadians are smokers. The association between LBP and smoking in the Canadian community has received limited attention in the current literature. ${ }^{1,8,28}$ In addition, the Canadian population is a multi-racial population; thus, results from studies done in other countries may have limited generalizability to Canadians. Studies such as this one are required to fill the knowledge gap regarding a possible association between daily smoking and LBP among adult Canadians.

We hypothesize that there is an association between daily smoking and the risk of LBP among adult Canadians between the ages of 20 and 59 years. The primary objective of our study is to examine the prevalence of LBP among daily smokers compared to non-smokers. The secondary objectives include assessing the risk of LBP among occasional smokers and identifying the prevalence of LBP in relation to age, sex, BMI, education and level of activity. We took into consideration the most consistent covariates in the literature (age, sex, BMI, activity and education) and also examined the possibility that these covariates are effect modifiers in the relationship between daily smoking and LBP.

In this study, we used data from the Canadian Community Health Survey (cycle 3.1) (CCHS-3.1). Our study is the first, to the authors' knowledge, to assess the relationship between
LBP and smoking exposure among adult Canadians using a large sample size.

Another unique feature of this study is that it examined the possibility that the covariates may be effect modifiers. To our knowledge, none of the existing studies performed statistical analysis to determine effect modification.

\section{Material and methods Study population}

The CCHS-3.1 survey was conducted by Statistics Canada between January and December 2005. This survey was crosssectional and covered approximately $98 \%$ of the Canadian population aged 12 and over who were living in privately occupied dwellings from 122 different health regions.

Individuals living on Indian reserves, Crown Land or institutional residence, fulltime members of the Canadian armed forces and residents of certain remote regions were excluded from the sampling frame due to limited accessibility. These groups account for less than $2 \%$ of the Canadian population, and it is not likely that their inclusion would have had a significant effect on the overall results.

The survey used a complex sampling strategy that involved both stratification and multiple stage selection. The survey had a $78.9 \%$ response rate, and 132,947 individuals responded to the survey.

The survey included questions related to health status, health care use and health determinants. Interviews were conducted either in person or over the phone. Interviewers were trained, and computer assisted interviewing was employed.

Participants aged 20 to 59 were selected from the CCHS 3.1 database because this age range excludes the pediatric population and people above 60 years who have an increased risk of cancer. Smoking status and the presence of LBP were assessed in the subjects, and information about possible confounders was also obtained.

\section{Exposure and outcome}

Participants were classified into three categories:

1. Daily smokers (current or former) were those who currently smoked or had smoked cigarettes daily and had smoked more than 100 cigarettes in their lifetime;

2. Non-smokers were those who had never smoked in their lifetime; and

3. Occasional smokers were those who currently smoked or used to smoke cigarettes occasionally and had smoked more than 100 cigarettes.

LBP was defined as having experienced LBP for more than six months and being diagnosed by a health care 
provider. Age, sex, BMI, level of activity and education level were identified and analyzed for each participant. Subjects were grouped into four age groups $(20-29,30-39,40-49$ and $50-59$ years).

BMI was calculated as follows:

BMI $=[$ weight (in kilograms) $] /[\text { height (in meters) }]^{2}$.

Obesity status was then determined using the World Health Organization (WHO) classification system, according to which a participant with a BMI of 30 or more was considered obese and those with a BMI of less than 30 were considered non-obese. ${ }^{29}$

Participants were classified as active if they participated in daily physical activity for at least 15 minutes and not active if they did not perform any physical activity or if their daily physical activity was less than 15 minutes. Participants were also assigned to one of two groups based on education level: a higher education group (participants who had been admitted to college or university and those with a post-secondary school certificate or diploma) and a lower education group (those who did not proceed beyond secondary education).

\section{Analytic methods and strategy}

The prevalence of LBP according to smoking status, age, sex, BMI, physical activity and level of education was calculated. Univariate and multivariate logistic regression were used to examine the relationship between smoking and LBP before and after adjustment for covariates. Odds ratios and their respective $95 \%$ confidence intervals were used to express the relationship.

Covariates were assessed for effect modification and confounding factors. Potential effect modifications were assessed by including multiplicative interaction terms in each model. Confounders were identified if they resulted in a $10 \%$ change in the odds ratio for the association. Effect modifiers, confounders and significant predictors of LBP were included in all models. Model parameters were estimated by using the method of maximum likelihood and were tested for significance using the Wald statistic.

Because the CCHS 3.1 survey was complex in its design, we took into account the national average design effect and relative sampling weights and were able to calculate the adjusted weight for the sample. ${ }^{30} \mathrm{All}$ of the statistical analyses were conducted using the statistical software package SAS, version $9.1 .^{31}$

\section{Results}

The study sample consisted of 73,507 individuals who provided valid responses to the survey. After weighting them to the
Canadian population (Table 1), the overall prevalence of LBP was $19.6 \%$. About one-third of our population consisted of non-smokers, while $46.8 \%$ of the population were classified as being daily smokers. The male to female ratio was almost 1:1. The majority of the study subjects had some post-secondary education, and $16 \%$ of the study population were obese. About one-third of the individuals in the study classified themselves as active persons.

In terms of smoking status (Table 2), the prevalence of LBP differed between the three groups: $23.3 \%$ of daily smokers had LBP, while $17.2 \%$ of occasional smokers and only $15.7 \%$ of non-smokers had LBP. Daily smokers had an approximately $40 \%$ increase in the prevalence of LBP compared to non-smokers $(P<0.0001)$.

Obesity and age were associated with an increase in the prevalence of LBP, and this effect was largely consistent among the three groups (daily smokers, occasional smokers and non-smokers). Individuals with high levels of education generally had lower rates of LBP in the three groups. Activity was associated with a decreased prevalence of LBP, but this effect was minor.

Univariate regression analyses demonstrated that smoking was a statistically significant predictor of LBP $(P<0.0001)$. In

Table I Epidemiologic characteristics of the study population

\begin{tabular}{lll}
\hline Characteristic & Number & Proportion* (\%) \\
\hline Low back pain status & & \\
LBP & 15,372 & 19.6 \\
No LBP & 58,135 & 80.4 \\
Smoking status & & \\
Daily smokers & & \\
(current or former) & 37,905 & 46.7 \\
Occasional smokers & & \\
(current or former) & 13,160 & 18.9 \\
Non-smokers & & \\
Sex & 22,442 & 34.4 \\
Male & & \\
Female & 35,242 & 51 \\
Age (yr) & 38,265 & 49 \\
20-29 & & \\
30-39 & 15,582 & 23.6 \\
40-49 & 18,812 & 23.6 \\
50-59 & 19,221 & 29.5 \\
Body mass index (BMI) & 19,892 & 23.33 \\
Non-obese & & \\
Obese & 59,817 & 84 \\
Education & 13,690 & 16 \\
Secondary education or less & 21,359 & 16 \\
Post-secondary education & 52,148 & 84 \\
Activity & & \\
Not active & 46,525 & 64.2 \\
Active & 26,982 & 35.8 \\
\hline
\end{tabular}

*Weighted to the Canadian population. 
Table 2 Prevalence of low back pain associated with smoking, age, sex, BMI, educational level and activity status

\begin{tabular}{|c|c|c|c|c|c|c|c|c|c|}
\hline & \multicolumn{3}{|c|}{$\begin{array}{l}\text { Daily smokers } \\
\text { (present or former) }\end{array}$} & \multicolumn{3}{|c|}{$\begin{array}{l}\text { Occasional smokers } \\
\text { (present or former) }\end{array}$} & \multicolumn{3}{|c|}{ Non-smokers } \\
\hline & No. & Cases & $\% *$ & No. & Cases & $\% *$ & No. & Cases & $\% *$ \\
\hline Total & 37,905 & 9,199 & 23.3 & 13,160 & 2,392 & 17.2 & 22,442 & 3,760 & 15.7 \\
\hline \multicolumn{10}{|l|}{ Sex } \\
\hline Male & 19,108 & 4,653 & 23.8 & 6,511 & $\mathrm{I}, \mathrm{I} 44$ & 16.2 & 9,634 & $\mathrm{I}, 507$ & 14.7 \\
\hline Female & 18,797 & 4,546 & 22.7 & 6,649 & $\mathrm{I}, 248$ & 18.2 & 12,808 & 2,253 & 16.7 \\
\hline \multicolumn{10}{|l|}{ BMI } \\
\hline Non-obese & 30,442 & 7,128 & 22.5 & 10,936 & $\mathrm{I}, 872$ & 16.1 & 18,470 & 2,902 & 15 \\
\hline Obese & 7,463 & 2,071 & 27.1 & 2,224 & 520 & 23.6 & 3,972 & 858 & 20.2 \\
\hline \multicolumn{10}{|l|}{ Age (yr) } \\
\hline $20-29$ & 6,826 & 1,296 & 18.1 & 3,087 & 342 & 11.8 & 5,673 & 624 & 10.4 \\
\hline 30-39 & 8,323 & $\mathrm{I}, 766$ & 20.9 & 3,789 & 612 & 15.9 & 6,697 & 1,046 & 15.2 \\
\hline $40-49$ & 10,838 & 2,793 & 25.3 & 3,240 & 698 & 19.7 & 5,145 & 991 & 18 \\
\hline $50-59$ & 11,918 & 3,344 & 26.4 & 3,044 & 740 & 22.5 & 4,927 & 1,099 & 21.2 \\
\hline \multicolumn{10}{|l|}{ Education } \\
\hline $\begin{array}{l}\text { Secondary } \\
\text { education or less }\end{array}$ & 13,479 & 3,439 & 24.8 & 2,861 & 568 & 18 & 5,004 & 940 & 18.2 \\
\hline $\begin{array}{l}\text { Post-secondary } \\
\text { education }\end{array}$ & 24,426 & 5,760 & 22.6 & 10,299 & $\mathrm{I}, 824$ & 17 & 17,348 & 2,820 & 15.1 \\
\hline \multicolumn{10}{|l|}{ Activity } \\
\hline Not active & 37,905 & 6,120 & 23.8 & 8,108 & I,506 & 17.5 & $|3,90|$ & 2,410 & 16.3 \\
\hline Active & 13,382 & 3,079 & 22.5 & 5,052 & 886 & 16.6 & 8,541 & $\mathrm{I}, 350$ & 14.8 \\
\hline
\end{tabular}

multivariate analyses, sex $(P<0.0001)$ and age $(P<0.0001)$ were found to be significant effect modifiers, while BMI $(P<0.001)$ and education $(P<0.0001)$ were significant confounders. Activity was found to be a marginally significant risk factor $(P=0.05)$.

Multivariate analysis, which took into account the effect modifiers (age and sex) and adjusted for risk factors (BMI, education and activity) (Table 3 ), demonstrated that among male daily smokers, those in the 20 to 29 year old age group had an OR of 1.87 (95\% CI $=1.62-2.17)$ of having LBP

Table 3 Unadjusted and adjusted ORs and 95\% Cls for LBP in relation to smoking by sex and age

\begin{tabular}{|c|c|c|c|c|}
\hline \multirow[t]{3}{*}{$\begin{array}{l}\text { Age } \\
(y r)\end{array}$} & \multicolumn{2}{|c|}{$\begin{array}{l}\text { Daily smokers } \\
\text { (present or former) }\end{array}$} & \multicolumn{2}{|c|}{$\begin{array}{l}\text { Occasional smokers } \\
\text { (present or former) }\end{array}$} \\
\hline & Unadjusted & Adjusted* & Unadjusted & Adjusted* \\
\hline & OR $95 \% \mathrm{Cl}$ & OR $95 \% \mathrm{Cl}$ & OR $95 \% \mathrm{Cl}$ & OR $95 \% \mathrm{Cl}$ \\
\hline
\end{tabular}

\section{Men}

$\begin{array}{lllllllllll}20-29 & 1.86 & 1.59-2.18 & 1.87 & 1.62-2.17 & \text { I.0I } & 0.8-1.24 & \text { I.07 } & 0.88-1.3\end{array}$

$\begin{array}{llllllllll}30-39 & I .5 & \text { I.34-I.7 } & \text { I.46 } & \text { I.29-I.66 } & 0.98 & 0.83-I .14 & 0.9 \mid & 0.77-I .07\end{array}$

$\begin{array}{lllllllllll}40-49 & 1.58 & 1.4-I .8 & I .69 & \text { I.52-I.89 } & \text { I.I3 } & 0.97-I .32 & \text { I.I7 } & \text { I.0I-I.36 }\end{array}$

$\begin{array}{llllllllll}50-59 & 1.53 & 1.3-1.75 & \text { I.57 } & \text { I.38-I.79 } & \text { I.39 } & \text { I.I3-I.59 } & \text { I.29 } & \text { I.07-I.54 }\end{array}$

Women

$\begin{array}{llllllllll}20-29 & \text { I.89 } & \text { I.66-2.15 } & \text { I.84 } & \text { I.6-2.II I } & 0.85-1.2 & \text { I.26 } & \text { I.06-I.5I }\end{array}$ $\begin{array}{llllllllll}30-39 & 1.43 & 1.28-1.6 & 1.36 & 1.2-1.54 & \text { I.09 } & 0.94-1.26 & 1.24 & 1.06-1.47\end{array}$ $\begin{array}{llllllllllll}40-49 & \text { I.36 } & \text { I.22-I.52 } & \text { I.36 } & \text { I.23-I.5। } & \text { I.I9 } & \text { I.02-I.38 } & \text { I.08 } & 0.93-I .26\end{array}$ $\begin{array}{lllllllllll}50-59 & \text { I.26 } & \text { I.I5-I.4 } & \text { I.I7 } & \text { I.05-I.3। } & \text { I.0I } & 0.89-I . I 6 & 0.97 & 0.82-I . I 4\end{array}$

*Adjusted for BMI, education and activity status. compared to non-smokers in the same age range (referent group). Daily smokers aged 30 to 39 years had an OR of 1.46 $(95 \% \mathrm{CI}=1.29-1.66)$. With increased age, there were smaller associations between LBP and daily smoking (Table 3).

A similar pattern was found among female daily smokers (Table 3). Those aged between 20 and 29 years had an OR of $1.84(95 \% \mathrm{CI}=1.6-2.11)$, while women aged 30 to 49 had an OR of $1.36(95 \% \mathrm{CI}=1.2-1.54)$. A similar trend toward a smaller association with LBP was observed as women aged.

In the male occasional smokers (Table 3), the increase in the odds of having LBP was significant only among men aged 40 to 59 years when compared to non-smokers within the same age range, while for female occasional smokers, the increase in the odds ratio was significant among the younger groups (20 to 39 year old) compared to female non-smokers in the same age group.

\section{Discussion}

This study examined the relationship between daily smoking and LBP using a large epidemiologic data set. The overall point prevalence of LBP among adult Canadians was $19.6 \%$. This finding is consistent with the current literature. ${ }^{4,10,13}$ The prevalence of LBP was about 50\% higher in daily smokers compared to non-smokers; after controlling for the influence of other known risk factors, daily smoking was still associated 
with an increased likelihood of having LBP. This finding is consistent with similar studies that were conducted in the USA. ${ }^{21,32}$ The exact mechanism for this finding is still unclear. However, several theories may explain why smokers might be prone to increased rates of LBP. The first theory is that smoking increases coughing and, thus, may predispose patients to disc herniation. ${ }^{18}$ Other theories focus on reduced blood flow to the discs and vertebral bodies, which has been found to correlate with both LBP and disc degeneration. ${ }^{19}$ Another theory is related to decreased bone mineral density associated with smoking, which has also been positively correlated with LBP. $^{20}$

Because age and sex are effect modifiers, the odds of having LBP were present among each stratum. The odds of having LBP were significantly higher when each stratum was compared to non-smokers of the same age and sex $(P<0.001)$. With increased age, the odds of having LBP among male and female daily smokers were reduced. This finding is likely due to the fact that the incidence of LBP from other causes, such as degenerative changes and lumbar canal stenosis, increases with age.

The association between daily smoking and LBP was more obvious in male daily smokers than in women. Men at different age groups had higher odds of having LBP, a finding which has had limited attention in the current literature..$^{25,33}$ This observation could be related to hormonal differences and may explain why sex is an effect modifier. More detailed studies should explore this possibility in more detail.

This study has shown that obesity is associated with an increased prevalence of LBP. Many studies have demonstrated the same finding. ${ }^{2,21}$ Obesity increases the load on the spine, which increases the risk of degenerative changes to the spine. We also found that activity had a limited effect on the prevalence of LBP. Kwon et al found that regular exercise reduced the prevalence of LBP. ${ }^{4}$ The difference between these outcomes could be related to the earlier study's small sample size and the fact that their findings were observed in individuals who exercised more than five times a week. Higher education was associated with a reduced prevalence of LBP, and most of the studies that have looked at education as a confounder found similar results. ${ }^{2,5}$

The effect of smoking was less obvious among occasional smokers. This finding was most likely due to variations in smoking consumption within this group. Identifying such variations was impossible using the available information from the survey. Despite this limitation, we found that occasional smoking increased the odds of having LBP in women aged 20 to 39 , but not in men in the same age group. This finding was similar to the findings of some previous studies. ${ }^{12}$ It is difficult to explain why the opposite trend was observed in older age groups.

Daily smokers had higher odds of having LBP than occasional smokers, which was consistent with the current literature and is most likely related to dose response. ${ }^{8,28}$ Deyo et al studied the influence of smoking on LBP and found that the prevalence of LBP increased with an increased number of packs and years of cigarette smoking. ${ }^{21}$ A more detailed study would be able to confirm this finding.

In this study, $46.7 \%$ of the participants were classified as current or former smokers. This high percentage was not surprising because of the high prevalence of smoking among Canadians in previous decades. For example, smoking prevalence among Canadians was 35\% in $1990 .{ }^{27}$

This study included most of the possible confounders that increase the risk of LBP. Other risk factors that were not included, such as work type, socioeconomic status and income, were partially adjusted for in our study by including the level of education and activity as confounders.

The present study has several advantages. The data represents the largest sample ever used in a population-based study of LBP and daily smoking among the Canadian population. In addition, this study included most of the possible confounders that increase the risk of LBP. Finally, the analyses take age and sex into account as effect modifiers.

A notable limitation of this study is that cause and effect could not be established. There is no way to determine if LBP is the result of daily smoking or a causative factor. Some cohort studies have indicated that smoking caused LBP in their cohort groups. ${ }^{12,22}$ The present study is based on self-reported data, which makes it vulnerable to misclassification bias.

In conclusion, this study from a large adult Canadian sample suggests that adult daily smokers are at high risk for experiencing LBP and that this risk is modified by age and sex, with younger smokers being at higher risk. This study also suggests a positive correlation between smoking dose and the risk of developing LBP.

\section{Disclosure}

The authors report no conflicts of interest in this work.

\section{References}

1. Coyte PC, Asche CV, Croxford R, Chan B. The economic cost of musculoskeletal disorders in Canada. Arthritis Care Res. 1998;11(5):315-325.

2. Rubin DI. Epidemiology and risk factors for spine pain. Neurol Clin. 2007;25(2):353-371.

3. Hestbaek L, Leboeuf-Yde C, Kyvik KO, Manniche C. The course of low back pain from adolescence to adulthood: Eight-year follow-up of 9600 twins. Spine. 2006;31(4):468-472. 
4. Kwon MA, Shim WS, Kim MH, Gwak MS, Hahm TS, Kim GS, et al. A correlation between low back pain and associated factors: A study involving 772 patients who had undergone general physical examination. J Korean Med Sci. 2006;21(6):1086-1091.

5. Cassidy JD, Cote P, Carroll LJ, Kristman V. Incidence and course of low back pain episodes in the general population. Spine. 2005;30(24): 2817-2823.

6. Goubert L, Crombez G, De Bourdeaudhuij I. Low back pain, disability and back pain myths in a community sample: Prevalence and interrelationships. Eur J Pain. 2004;8(4):385-394.

7. Jacob T. Low back pain incident episodes: A community-based study. Spine. 2006;6(3):306-310.

8. Cassidy JD, Carroll LJ, Cote P. The Saskatchewan health and back pain survey. the prevalence of low back pain and related disability in Saskatchewan adults. Spine. 1998;23(17):1860-1867.

9. Kopec JA, Sayre EC, Esdaile JM. Predictors of back pain in a general population cohort. Spine. 2004;29(1):70-78.

10. Deyo RA, Weinstein JN. Low back pain. $N$ Engl J Med. 2001;344(5): 363-370.

11. Kovacs FM, Gestoso M, Gil del Real MT, et al. Risk factors for nonspecific low back pain in schoolchildren and their parents: A population based study. Pain. 2003;103(3):259-268.

12. Mikkonen P, Leino-Arjas P, Remes J, et al. Is smoking a risk factor for low back pain in adolescents? A prospective cohort study. Spine. 2008;33(5):527-532.

13. Kaila-Kangas L, Leino-Arjas P, Riihimaki H, et al. Smoking and overweight as predictors of hospitalization for back disorders. Spine. 2003;28(16):1860-1868.

14. Heliovaara M, Knekt P, Aromaa A. Incidence and risk factors of herniated lumbar intervertebral disc or sciatica leading to hospitalization. J Chronic Dis. 1987;40(3):251-258.

15. Iwahashi M, Matsuzaki H, TokuhashiY, et al. Mechanism of intervertebral disc degeneration caused by nicotine in rabbits to explicate intervertebral disc disorders caused by smoking. Spine. 2002;27(13):1396-1401.

16. Nemoto Y, Matsuzaki H, Tokuhasi Y, et al. Histological changes in intervertebral discs after smoking and cessation: Experimental study using a rat passive smoking model. J Orthop Sci. 2006;11(2):191-197.

17. Uei H, Matsuzaki H, Oda H, et al. Gene expression changes in an early stage of intervertebral disc degeneration induced by passive cigarette smoking. Spine. 2006;31(5):510-514.

18. Kelsey JL. An epidemiological study of acute herniated lumbar intervertebral discs. Rheumatol Rehabil. 1975;14(3):144-159.
19. Kauppila LI, Tallroth K. Postmortem angiographic findings for arteries supplying the lumbar spine: Their relationship to low-back symptoms. J Spinal Disord. 1993;6(2):124-129.

20. Hopper JL, Seeman E. The bone density of female twins discordant for tobacco use. N Engl J Med. 1994;330(6):387-392.

21. Deyo RA, Bass JE. Lifestyle and low-back pain. the influence of smoking and obesity. Spine. 1989;14(5):501-506.

22. Feldman DE, Rossignol M, Shrier I, Abenhaim L. Smoking. A risk factor for development of low back pain in adolescents. Spine. 1999;24(23): 2492-2496.

23. Leboeuf-Yde C, Kyvik KO, Bruun NH. Low back pain and lifestyle. part I: Smoking. information from a population-based sample of 29,424 twins. Spine. 1998;23(20):2207-2214.

24. Webb R, Brammah T, Lunt M, et al. Prevalence and predictors of intense, chronic, and disabling neck and back pain in the UK general population. Spine. 2003;28(11):1195-1202.

25. Smith BH, Elliott AM, Hannaford PC, et al. Factors related to the onset and persistence of chronic back pain in the community: Results from a general population follow-up study. Spine. 2004;29(9):1032-1040.

26. Goldberg MS, Scott SC, Mayo NE. A review of the association between cigarette smoking and the development of nonspecific back pain and related outcomes. Spine. 2000;25(8):995-1014.

27. Smoking rates: Canadian tobacco use monitoring survey (CTUMS); http://www.hc-sc.gc.ca/hl-vs/tobac-tabac/research-recherche/stat/ ctums-esutc_2006_e.html.

28. Carroll LJ, Cassidy JD, Cote P. The sSskatchewan health and back pain survey: The prevalence and factors associated with depressive symptomatology in Saskatchewan adults. Can J Public Health. 2000;91(6):459-464.

29. Obesity classification. http://www.who.int.

30. Chen Y, Dales R, Krewski D, Breithaupt K. Increased effects of smoking and obesity on asthma among female canadians: The national population health survey, 1994-1995. Am J Epidemiol. 1999;150(3):255-262.

31. SAS Institute Inc. SAS;9.1.

32. Gyntelberg F. One year incidence of low back pain among male residents of copenhagen aged 40-59. Dan Med Bull. 1974;21(1):30-36.

33. Scott SC, Goldberg MS, Mayo NE, et al. The association between cigarette smoking and back pain in adults. Spine. 1999;24(11):1090-1098.
Journal of Pain Research

\section{Publish your work in this journal}

The Journal of Pain Research is an international, peer-reviewed, open access, online journal that welcomes laboratory and clinical findings in the fields of pain research and the prevention and management of pain. Original research, reviews, symposium reports, hypothesis formation and commentaries are all considered for publication.

\section{Dovepress}

The manuscript management system is completely online and includes a very quick and fair peer-review system, which is all easy to use. Visit http://www.dovepress.com/testimonials.php to read real quotes from published authors. 